\title{
Association between Uterine Fibroid and Benign Thyroid Disease: Nationwide Population-Based Cohort Study
}

Jin-Sung Yuk

Inje University Sanggye Paik Hospital

Jung Min Kim ( $\nabla$ jmkim.benaiah@paik.ac.kr)

Inje University Sanggye Paik Hospital

\section{Research Article}

Keywords: uterine myoma, uterine fibroid, hypothyroidism, thyroid goiter, thyroid nodule

Posted Date: September 16th, 2021

DOl: https://doi.org/10.21203/rs.3.rs-888322/v1

License: (c) (1) This work is licensed under a Creative Commons Attribution 4.0 International License.

Read Full License 


\section{Abstract \\ Background}

Uterine fibroid and benign thyroid disease are common diseases in women.

\section{Objective}

This study aims to evaluate both diseases are related.

\section{Study Design:}

We established the uterine fibroid group according to diagnosis codes and surgery codes using the Korea National Health Insurance data from 2007 to 2020. All women from 20 to 50 years old with uterine myomectomy from 2007 to 2020 were identified (uterine fibroids group). For controls, 1:1 propensity score matching was performed on age at 5-year intervals, socio-economic status (SES), region, Charlson comorbidity index (CCl), and menopause (control group). Thyroid disease cases were selected using the thyroid disease diagnosis code and thyroid-associated laboratory examination.

\section{Results}

A total of 21,246 patients were extracted from the uterine fibroid and control groups, respectively. The median ages of each group were 40 (range, $35 \sim 44$ ) years and 40 (range, $35 \sim 44$ ) years old. Benign thyroid disease was $469(2.2 \%)$ in the uterine fibroid group and $246(1.2 \%)$ in the control group. Among benign thyroid diseases, hypothyroidism was the largest in both groups. A non-toxic single thyroid nodule followed it. The uterine fibroid group had a higher incidence of hypothyroidism \{relative risk (RR) 1.943, $95 \% \mathrm{Cl} 1.5-2.516$ ), autoimmune thyroid disease (RR 1.59, 95\% Cl 1.065-2.373), goiter (RR 1.773, 95\% Cl 1.051-2.99), nontoxic single thyroid nodule (RR 2.213, 95\% Cl 1.685-2.907), other thyroid disease (RR $2.31,95 \% \mathrm{Cl} 1.608-3.317$ ), and total thyroid disease (RR 1.905, 95\% $\mathrm{Cl} 1.63-2.226$ ) in logistic regression analysis adjusted for age, SES, region, $\mathrm{CCl}$, and menopause compared than the control group. The uterine fibroid group had a higher risk of hypothyroidism (HR 1.431, 95\% $\mathrm{Cl} 1.023-2.001)$ and nontoxic single thyroid nodule $(\mathrm{HR} 1.511,95 \% \mathrm{Cl})$ in cox regression adjusted for age, SES, region, $\mathrm{CCl}$, and menopause.

\section{Conclusions}

Uterine fibroid might be associated with hypothyroidism and thyroid nodule.

\section{Introduction}


Uterine fibroid, also called myoma, is the most common gynecological benign tumor in premenopausal women. ${ }^{1}$ It consists mostly of monoclonal cells from the myometrium, the smooth muscle layer of the uterus, fibroblasts, and the extracellular matrix. Uterine fibroid occurs more frequently in black women, early menarche, contraceptives from less than 16 years of age, and a high body mass index (BMI). Uterine fibroid expresses more estrogen receptors and progesterone receptors than normal myometrium. Ovarian steroids, estradiol, and progesterone promote the growth of uterine fibroids.

Thyroid disease is known to have a high prevalence among women with subfertility, with $5 \sim 7 \%$ in subclinical hypothyroidism, $2 \sim 4.5 \%$ in overt hypothyroidism, $0.5 \sim 1.0 \%$ in overt hyperthyroidism, and 5 $\sim 10 \%$ in thyroid autoimmune diseases. ${ }^{2}$

Thyroid dysfunction is more common in women than men. This appears to be due to sex differences in immune function, as in many autoimmune diseases. More than $80 \%$ of patients with thyroiditis and its resulting hypothyroidism have anti-thyroid antibodies. ${ }^{3}$ According to US data, thyroid autoantibodies to thyroid peroxidase are found in $3 \%$ of teenage males, $7 \%$ of teenage females, $12 \%$ of males over 80 years of age, and $30 \%$ of females. ${ }^{4}$

Little is known about uterine fibroid and thyroid disease. In a study in 1989, women who have undergone a hysterectomy for uterine fibroids had significantly more frequent pathological thyrotrophin-releasing hormone (TRH)/thyroid stimulating hormone (TSH) stimulation test results and more anti-peroxidase antibody and/or thyroglobulin antibodies compared to the control group. ${ }^{5}$ Recent studies showed that women with fibroids had a higher risk of thyroid cancer ${ }^{6}$ and thyroid nodules. ${ }^{7,8}$ It was reported the association between fibroids and overt hypothyroidism. ${ }^{9}$ However, these studies have limitations, such as a study with a small number of patients ${ }^{7,8}$, a study not performing propensity matching although largescale national data ${ }^{6}$, and not a comprehensive study of benign thyroid disease. ${ }^{6-9}$

Using a nationwide population-based database for a cohort study can provide significantly more data than a cohort-based on multiple institutions. Therefore, this study aimed to evaluate the relationship between uterine fibroid and benign thyroid disease using Korean Health Insurance Review and Assessment Service (HIRA) data.

\section{Materials \& Methods}

\section{Database}

i. Korea provides national health insurance services to all Koreans (about 51 million people) by law. ${ }^{10}$ Therefore, Korea's National Health Insurance Corporation provides medical information for most diseases (diagnosis code, operation code, laboratory examination code, prescription drug information, type of medical insurance, region, hospital), except for exceptional cases such as cosmetic surgery. Medical institutions in Korea make a claim to the Korea Health Insurance Corporation for medical insurance costs. Since there may be disputes over medical expenses between medical institutions and the Korea Health 
Insurance Corporation, the agency that mediates them is HIRA. Therefore, HIRA has most of the national health insurance information in Korea. HIRA data is publicly available. HIRA data can be requested from the HIRA data site (http://opendata.hira.or.kr).

ii. This retrospective cohort study used health insurance data provided by HIRA from July 1,2007 , to June $31,2020$.

\section{Selection of participants}

i. In this study, Korea Health Insurance Medical Care Expenses (2016, 2019 version) was used to select subjects and outcomes for surgery and examination codes. The International Classification of Diseases, 10th revision (ICD-10) for diagnosis codes was used.

ii. This study selected the uterine fibroid group, 20 50 years old women, with the code for diagnosing uterine fibroids (D25.x) and the code for myomectomy (R4121 9). In addition, to increase the experimental group's accuracy, only women who visited medical institutions more than 2 times for uterine fibroids were extracted.

iii. As a control group, women aged 20 50 years who underwent appendectomy (Q2861/Q2862/Q2863) were extracted. Among these women, if there was a diagnosis code (D25.x) of uterine fibroids at least once in whole cohort, they were excluded from the study.

iv. For the subjects thus extracted, 1:1 propensity score matching was performed on age at 5-year intervals, socio-economic status (SES), region of residence, Charlson comorbidity index (CCI), and menopause.

\section{Outcome}

i. A patient with thyroid disease is defined to visit medical institutions 3 times with thyroid diagnosis code and to be performed thyroid-related tests (thyroid scan, triiodothyronine (T3), free T3, T3 uptake, reverse T3, thyroxine (T4), free T4, thyroglobulin, TSH, anti-peroxidase antibody, ant-thyroglobulin antibody, thyroid function test, thyroid-stimulating immunoglobulin, T4-binding globulin, thyroid sonography).

ii. Thyroid diseases are largely divided into the hypothyroid group (E03.4, E03.5, E03.8, E03.9), hyperthyroidism (E05.0, E05.1, E05.2, E05.5, E05.8, E05.9), autoimmune thyroid group (E06.2, E06.3, E06.5, E06.9), goiter group (E04.0, E04.2, E04.8, E04.9), nodular group (E04.1) and others (E07.8, E07.9).

\section{Variables}

i. The independent variables were age at surgery, SES, and region. Ages were categorized into 5-year intervals. When the type of medical insurance was medical aid, which corresponds to Medicaid in the United States, it was defined as low SES. If the location of the medical institution was not metropolitan, it was defined as a rural region. 
ii. Comorbidity was calculated using the diagnosis code from 1 year before the date of participation to the date of participation in the study, using the method of Quan et al. to calculate the CCl (Quan et al., 2011).

\section{Statistics}

i. All statistics mainly used SAS Enterprise Guide 6.1 (SAS Institute Inc). As a supplement, R 3.0.2 (The R Foundation for Statistical Computing) was used.

ii. A two-sided test was performed for all statistics in this study. Statistical significance was defined when the $p$-value was less than or equal to 0.05 .

iii. In this study, paired t-test (parametric) and Wilcoxon signed-rank test (nonparametric) were used to analyze continuous variables, and Cochran-Mantel-Haenszel test was used to analyze categorical variables.

iv. In this study, conditional logistic regression analysis was performed for the adjustment of various confounding factors.

v. Stratified Cox-regression analysis was performed in addition to conditional logistic regression analysis to confirm the robustness of our study results.

vi. When the missing value was less than $10 \%$, the listwise deletion method was performed, and when the missing value was more than $10 \%$, the regression imputation method was performed.

\section{Ethics}

i. The study was approved by the Institutional Review Board of Inje University Sanggye Paik Hospital (No.: SGPAIK 2021-02-005). As this data is public and non-personally identifiable, the Institutional Review Board of Inje University Sanggye Paik Hospital IRB has approved not requiring the informed consent.

ii. The data used in this study were provided after removing variables that could identify individuals in HIRA. In addition, data analysis in this study can only be done on HIRA's server, and raw data cannot be exported. Therefore, since it is impossible to specify the individual included in the data, there is no harm to the individual included in the data. This study does not disadvantage the involved individuals because the data did not contain personally identifiable information. Therefore, this study did not require informed consents from subjects according to the Bioethics and Safety Act of South Korea. This study was conducted in accordance with the guidelines of the South Korea's Bioethics and Safety Act.

iii. Although this study uses data provided by HIRA, HIRA and the Korean Ministry of Health and Welfare have no conflict of interest in this study.

\section{Results}




\section{Clinical characteristics (Fig. 1, Table 1)}

In this study, 21,246 patients were extracted from the uterine fibroid and control groups, respectively (Fig. 1). The median age of each group is 40 (range, $35 \sim 44$ ) years and 40 (range, $35 \sim 44$ ) years, and the detailed characteristics of the patients are shown in Table 1.

\section{Thyroid disease in women with the uterine fibroid group or control group (Table 2)}

Benign thyroid disease was $469(2.2 \%)$ in the uterine fibroid group and $246(1.2 \%)$ in the control group (Table 2). Among benign thyroid diseases in both groups, hypothyroidism was the largest, followed by a non-toxic single thyroid nodule.

\section{Conditional logistic regression analysis of thyroid disease in women with uterine fibroids (Fig. 2)}

In logistic regression analysis adjusted for age, SES, region, $\mathrm{CCl}$, menopause, etc., the uterine fibroid group had a significantly higher incidence of hypothyroidism \{Relative risk (RR) 1.943, 95\% confidence interval (Cl) $1.5 \sim 2.516$, autoimmune thyroid disease (RR 1.59, 95\% Cl $1.065 \sim 2.373$ ), Goiter (RR 1.773, 95\% Cl 1.051 2.99), Nontoxic single thyroid nodule (RR 2.213, 95\% Cl $1.685 \sim 2.907$ ), Other thyroid diseases (RR 2.31, 95\% Cl $1.608 \sim 3.317$ ), and total thyroid disease (RR 1.905, 95\% Cl $1.63 \sim 2.226$ ) (Fig. 2). On the other hand, there was no difference in the incidence of hyperthyroidism (RR 1.094, 95\% Cl 0.754-1.588).

\section{Cox-regression analysis of thyroid disease in women with uterine fibroids (Table 3)}

In Cox-regression analysis adjusted for age, SES, region, $\mathrm{CCl}$, menopause, etc., the uterine fibroid group had a significantly higher risk of hypothyroidism \{Hazard ratio (HR) 1.431, 95\% Cl $1.023 \sim 2.001\}$, Nontoxic single thyroid nodule (HR 1.511, 95\% Cl 1.037 2.202), Other thyroid diseases (HR 1.826, 95\% $\mathrm{Cl} 1.098$ 3.036), and Total thyroid disease (HR 1.393, 95\% Cl $1.13 \sim 1.718$ ) (Table 3).

\section{Discussion}

\section{Principal findings:}

This study evaluated if uterine fibroids are associated with benign thyroid diseases, such as hypothyroidism, autoimmune thyroiditis, thyroid goiter, thyroid nodule, or hyperthyroidism. Conditional logistic regression analysis showed that uterine fibroids were significantly associated with hypothyroidism, autoimmune thyroiditis, thyroid goiter, thyroid nodule, except for hyperthyroidism and autoimmune thyroid disease. Cox-regression analysis showed that uterine fibroids were significantly associated with hypothyroidism and thyroid nodule.

\section{Results:}


Previous studies have evaluated the association between uterine fibroids and thyroid diseases ${ }^{6-9}$. Patients with uterine fibroids had significantly more thyroid nodules. ${ }^{7,8}$ Another study showed overt hypothyroidism was associated with the presence of uterine fibroids. ${ }^{9}$ In an analysis using the national health insurance research database of Taiwan, like this study, Sun et al. reported that uterine fibroids increased the risk of thyroid cancer. ${ }^{6}$ Our findings are consistent with the previous studies showing that patients with uterine fibroids had more benign thyroid diseases such as hypothyroidism and thyroid nodules.

\section{Clinical Implications:}

Why is the incidence of benign thyroid diseases high in patients with uterine fibroids? What are the common causative factors of uterine fibroids and benign thyroid disease?

First, considering the relationship between uterine fibroids and thyroid nodules, female hormones would be a common cause of them.

Uterine fibroids are mainly composed of an extracellular matrix, have a low mitotic index, and are usually known to grow slowly. ${ }^{11}$ Uterine fibroids are more common in premenopausal women, and their risk factors include early menarche, contraceptives from the age of 16, and high BMI. ${ }^{1}$ Estradiol and progesterone promote the growth and the size of uterine fibroids. ${ }^{12}$ Uterine fibroids are more responsive to female hormones than normal myometrium. Its cause would be that uterine fibroids express more estrogen receptors (ERs) and progesterone receptors than normal myometrium. ${ }^{13}$ As such, uterine fibroids could be estrogen-dependent diseases.

So what about benign thyroid disease? Thyroid disease is also more prevalent between puberty and menopause. ${ }^{14}$ Thyroid nodules or thyroid cancer are three times more common in women. ${ }^{14,15}$ Growth of benign thyroid nodules slowed after menopause. ${ }^{16}$ Women who had menopause over 55 years of age had more thyroid nodules than women who had menopause under 50 years of age. Women with a reproductive year of 40 years or more had a higher risk of thyroid nodules than women with a reproductive year less than 35 years of age. ${ }^{17}$ These epidemiological data suggest the effect of estrogen on thyroid disease. Factors estimated to be high in estrogen exposure, such as uterine fibroids and reproductive years, were found to increase the risk of thyroid cancer. ${ }^{18}$

Estrogen promotes cell growth in primary cultures of human thyrocytes from benign and malignant thyroid nodules and in thyroid cancer cell lines. ${ }^{19,20}$ Estrogen enhances the metastatic properties of thyroid cells, including adhesion, migration, invasiveness, and promotes proliferation. ${ }^{21}$ Estrogen promotes growth through both ERa and ER $\beta$ in thyroid cells. Still, in thyroid cancer cells, ERa is increased, promoting tumorigenesis, and ER $\beta$ is decreased, thus acting as a tumor suppressor. ${ }^{20} \mathrm{ERa}$ is also increased in uterine fibroids. ${ }^{22}$ Estrogen interacts with ER in immune cells and alters apoptotic pathways such as Bcl-2 family proteins' activity and nuclear factor kappa B's activity. ${ }^{20,23,24}$ 
In summary, estrogen can be seen as a cause of increasing thyroid nodules, including thyroid cancer, but the causal relationship and mechanism are unclear

Second, lodine may consider as a factor in the association between uterine fibroids and thyroid goiters that has been previously known. ${ }^{9}$ lodine is a trace element and is reduced to iodide and absorbed in the stomach and duodenum. lodide is uptaken into tissues through sodium iodide symporter (NIS) in the thyroid gland, ovary, uterine endometrium, stomach, and breast. ${ }^{25} \mathrm{NIS}$ is important for thyroid iodine uptake and thyroid hormone synthesis. ${ }^{26}$ Estrogen lowered NIS gene expression ${ }^{27}$, and lowered iodide uptake $^{28}$, so insufficient iodine intake may be a factor in the development of goiter and hypothyroidism.

It is well known that iodine deficiency causes goiter. lodine deficiency also increases estrogen activity. lodine deficiency decreases cytochrome P4501A1 and 1B1. It results in a decrease in estrone and estradiol metabolism. In addition, iodine deficiency causes estrogen-induced transcription by lowering the activity of BRCA1, an inhibitor of ERa transcription. ${ }^{29}$ Therefore, iodine deficiency may cause an increase in estrogen, which causes both thyroid goiter and uterine fibroids. However, since Korea is not an iodinedeficient country, ${ }^{30}$ this explanation does not seem reasonable. Also, the prevalence of goiter showed no gender difference in iodine-sufficient regions. ${ }^{31}$ However, this part is controversial because there is no information on iodine intake, such as urine iodine amount in the target group of this study.

Third, what can explain the relationship between uterine fibroids and hypothyroidism?

Another study showed a relationship between uterine fibroids and overt hypothyroidism, and the overt hypothyroidism group had a larger uterine fibroid than the normal thyroid group. However, uterine fibroids did not associate with anti-thyroid antibodies. ${ }^{9}$ If so, would not the lack of thyroid hormone itself, like iodine deficiency, be the reason for uterine fibroids?

The thyroid hormone has an important role in the regulation of ovarian function. In the rat experiment, thyroid hormone regulates the response of the uterus to estrogen, mainly by modulating uterine estrogen receptor expression and uterine estrogen-induced peroxidase activity. ${ }^{32}$ Thyroid dysfunction leads to menstrual and ovulatory disturbances. ${ }^{33}$ Overt hypothyroidism increases peripheral aromatization, decreases sex hormone-binding globulin, decreases estradiol concentrations, and increases unbound fraction form. Therefore, hypothyroidism might affect uterine fibroids through female hormones because hypothyroidism causes a increase in estrogen like effect.

Overt hypothyroidism induces ovulatory dysfunction by impairing pulsatile secretion of $\mathrm{GnRH}$ by raising the concentration of prolactin and causes insufficient corpus luteum with low progesterone production. In a study of explants cultures, TSH increased prolactin production in myometrium and uterine fibroids and increased more in uterine fibroids than in myometrium. ${ }^{34}$ Since uterine fibroids have many prolactin receptors, ${ }^{35}$ elevated prolactin due to overt hypothyroidism might have a direct effect to uterine fibroids. 
Smooth muscle cell proliferation has been reported after TSH stimulation. ${ }^{36}$ It was found that thyroid hormone receptor in rat uterus, ${ }^{37}$ thyrotropin-releasing hormone, TSH, thyroid hormone receptor in monkey uterus, ${ }^{38}$ and binding site presumed to be T3 receptor in human myometrium. ${ }^{39}$ Elevated TSH, as with hypothyroidism, might increase the likelihood of developing uterine fibroids.

Uterine fibroids can be attributed to systemic immune environments with predominantly chronic inflammatory conditions, predominantly T-helper cytokines. ${ }^{40}$ Pro-inflammatory molecules also appear in hypothyroidism conditions. ${ }^{41}$ Also, the common cause of hypothyroidism is autoimmune thyroiditis. Autoimmune thyroiditis is defined as the presence of anti-peroxidase antibody or anti-thyroglobulin antibody in a patient with goiter, or a finding that is consistent with chronic thyroiditis on ultrasonography, or a finding of chronic thyroiditis on fine-needle aspiration. Autoimmune thyroiditis occurs due to dysregulation of the immune system, resulting in immune attacks with chronic inflammation in the thyroid gland. Autoimmune thyroiditis is classified as a T-cell mediated organ-specific autoimmune disorder. Although the association between autoimmune thyroiditis and uterine fibroids is not well known, autoimmune thyroiditis has a high prevalence in patients with idiopathic subfertility, ${ }^{42}$ polycystic ovarian syndrome, ${ }^{43}$ diminished ovarian reserve, ${ }^{44}$ premature ovarian insufficiency. ${ }^{45}$

In summary, autoimmune thyroiditis is closely related to obstetrics and gynecological diseases such as infertility and polycystic ovarian syndrome. Although the detailed mechanism is not known, it is thought to be an immune mechanism. Although the association autoimmune thyroiditis with uterine fibroids is not well known, it is possible due to an immune mechanism like other obstetrics and gynecological diseases. Taken together, the chronic inflammatory environment might be responsible for both uterine fibroids and hypothyroidism. Cox-regression analysis of this study, however, showed that uterine fibroids were not significantly associated with autoimmune thyroid disease. Autoimmune thyroiditis is a common cause of hypothyroidism, and many physicians can be likely to select the diagnostic code for hypothyroidism. However, it does not seem easy to distinguish them in this study.

\section{Research Implications}

Future studies that prospectively follow women with uterine fibroids across a lifetime would overcome the limitations of our analysis.

\section{Strengths and Limitations}

This study has some limitations. First, there can be an inaccuracy in the diagnosis. A diagnosis code does not mean a disease. Diagnosis codes are likely to be inaccurate as they were collected to reimburse healthcare services. As mentioned before, it is likely that autoimmune thyroiditis was only labeled as diagnosis code 'hypothyroidism.' Second, HIRA data does not deal with specific information about the patient. We could not detect or correct changes caused by external interference other than disease, such as drugs. We could not correct BMI, family history, etc. Third, Surveillance bias may exist in this study. Compared to the control appendectomy group, patients who have undergone myomectomy for uterine fibroids have more chances to visit the medical staff and have more examinations before surgery, so they 
are more likely to be diagnosed with other diseases. However, since the thyroid dysfunction itself causes symptoms such as changes in the menstrual cycle and menstrual volume, the possibility of surveillance bias is considered to be low. Fourth, this study is limited to the treatment group that has undergone myomectomy, so there is a limitation that it cannot represent all patients with uterine fibroids.

However, this study has strength because this study analyzed a large number of patients. As HIRA data is a large-scale national health insurance database, this study has representativeness of the Korean population. The Patient Samples are comprehensive but also contain specific information, such as prescribed medications. Because The Patient Samples passed the validity test, it is effective for estimating the entire population.

\section{Conclusions}

In conclusion, uterine fibroids could be associated with benign thyroid diseases, such as hypothyroidism, autoimmune thyroiditis, thyroid goiter, thyroid nodule, except for hyperthyroidism and autoimmune thyroid disease. Especially, uterine fibroids were significantly associated with hypothyroidism and thyroid nodule in Cox-regression analysis. Therefore, we suggest that patients with uterine fibroids could have more hypothyroidism, and thyroid nodule.

\section{Declarations}

\section{Author contributions}

Study conception and design; J.S.Y. Acquisition of data; J.S.Y. Analysis and interpretation of data; J.S.Y., J.M.K. Drafting of the manuscript; J.M.K. Critical revision; J.S.Y., J.M.K.

Additional information

Competing interest: The authors declare no competing interest.

Funding Source: None

\section{References}

1. Stewart EA, Laughlin-Tommaso SK, Catherino WH, Lalitkumar S, Gupta D, Vollenhoven B. Uterine fibroids. Review. Nat Rev Dis Primers. Jun 23 2016;2:16043. doi:10.1038/nrdp.2016.43

2. Valdes S, Maldonado-Araque C, Lago-Sampedro A, et al. Population-Based National Prevalence of Thyroid Dysfunction in Spain and Associated Factors: Di@bet.es Study. Research Support, Non-U.S. Gov't. Thyroid. Feb 2017;27(2):156-166. doi:10.1089/thy.2016.0353

3. Spencer CA, Hollowell JG, Kazarosyan M, Braverman LE. National Health and Nutrition Examination Survey III thyroid-stimulating hormone (TSH)-thyroperoxidase antibody relationships demonstrate that 
TSH upper reference limits may be skewed by occult thyroid dysfunction. Research Support, N.I.H., Extramural. J Clin Endocrinol Metab. Nov 2007;92(11):4236-40. doi:10.1210/jc.2007-0287

4. Hollowell JG, Staehling NW, Flanders WD, et al. Serum TSH, T(4), and thyroid antibodies in the United States population (1988 to 1994): National Health and Nutrition Examination Survey (NHANES III). J Clin Endocrinol Metab. Feb 2002;87(2):489-99. doi:10.1210/jcem.87.2.8182

5. Lange R, Meinen K. [Diagnosis of thyroid function in uterine myomatosis]. Zentralb/ Gynakol. 1989;111(1):47-52. Schilddrusenfunktionsdiagnostik bei Myomatosis uteri.

6. Sun LM, Chung LM, Lin CL, Kao CH. Uterine Fibroids Increase the Risk of Thyroid Cancer. Research Support, Non-U.S. Gov't. Int J Environ Res Public Health. May 28 2020;17(11)doi:10.3390/ijerph17113821

7. Kim MH, Park YR, Lim DJ, et al. The relationship between thyroid nodules and uterine fibroids. Endocr J. 2010;57(7):615-21. doi:10.1507/endocrj.k10e-024

8. Spinos N, Terzis G, Crysanthopoulou A, et al. Increased frequency of thyroid nodules and breast fibroadenomas in women with uterine fibroids. Thyroid. Dec 2007;17(12):1257-9. doi:10.1089/thy.2006.0330

9. Ott J, Kurz C, Braun R, et al. Overt hypothyroidism is associated with the presence of uterine leiomyoma: a retrospective analysis. Eur J Obstet Gynecol Reprod Biol. Jun 2014;177:19-22. doi:10.1016/j.ejogrb.2014.03.003

10. Kim L, Kim JA, Kim S. A guide for the utilization of Health Insurance Review and Assessment Service National Patient Samples. Epidemiol Health. 2014;36:e2014008. doi:10.4178/epih/e2014008

11. Kawaguchi K, Fujii S, Konishi I, Nanbu Y, Nonogaki H, Mori T. Mitotic activity in uterine leiomyomas during the menstrual cycle. Am J Obstet Gynecol. Mar 1989;160(3):637-41. doi:10.1016/s00029378(89)80046-8

12. Ghosh S, Naftalin J, Imrie R, Hoo WL. Natural History of Uterine Fibroids: A Radiological Perspective. Review. Curr Obstet Gynecol Rep. 2018;7(3):117-121. doi:10.1007/s13669-018-0243-5

13. Doherty L, Mutlu L, Sinclair D, Taylor H. Uterine fibroids: clinical manifestations and contemporary management. Review. Reprod Sci. Sep 2014;21(9):1067-92. doi:10.1177/1933719114533728

14. Li N, Du XL, Reitzel LR, Xu L, Sturgis EM. Impact of enhanced detection on the increase in thyroid cancer incidence in the United States: review of incidence trends by socioeconomic status within the surveillance, epidemiology, and end results registry, 1980-2008. Research Support, N.I.H., Extramural

Review. Thyroid. Jan 2013;23(1):103-10. doi:10.1089/thy.2012.0392 
15. Enewold L, Zhu K, Ron E, et al. Rising thyroid cancer incidence in the United States by demographic and tumor characteristics, 1980-2005. Research Support, N.I.H., Intramural

Research Support, Non-U.S. Gov't

Research Support, U.S. Gov't, Non-P.H.S. Cancer Epidemiol Biomarkers Prev. Mar 2009;18(3):784-91. doi:10.1158/1055-9965.EPI-08-0960

16. Costante G, Crocetti U, Schifino E, et al. Slow growth of benign thyroid nodules after menopause: no need for long-term thyroxine suppressive therapy in post-menopausal women. Clinical Trial

Controlled Clinical Trial. J Endocrinol Invest. Jan 2004;27(1):31-6. doi:10.1007/BF03350907

17. Wang $\mathrm{K}$, Yang $\mathrm{Y}, \mathrm{Wu} \mathrm{Y}$, Chen J, Zhang D, Liu C. The association of menstrual and reproductive factors with thyroid nodules in Chinese women older than 40 years of age. Research Support, Non-U.S. Gov't. Endocrine. Mar 2015;48(2):603-14. doi:10.1007/s12020-014-0342-7

18. Braganza MZ, de Gonzalez AB, Schonfeld SJ, Wentzensen N, Brenner AV, Kitahara CM. Benign breast and gynecologic conditions, reproductive and hormonal factors, and risk of thyroid cancer. Research Support, N.I.H., Intramural. Cancer Prev Res (Phila). Apr 2014;7(4):418-25. doi:10.1158/1940-6207.CAPR13-0367

19. Kumar A, Klinge CM, Goldstein RE. Estradiol-induced proliferation of papillary and follicular thyroid cancer cells is mediated by estrogen receptors alpha and beta. Research Support, N.I.H., Extramural

Research Support, Non-U.S. Gov't. Int J Oncol. May 2010;36(5):1067-80. doi:10.3892/ijo_00000588

20. Chen GG, Vlantis AC, Zeng Q, van Hasselt CA. Regulation of cell growth by estrogen signaling and potential targets in thyroid cancer. Research Support, Non-U.S. Gov't

Review. Curr Cancer Drug Targets. Aug 2008;8(5):367-77. doi:10.2174/156800908785133150

21. Rajoria S, Suriano R, Shanmugam A, et al. Metastatic phenotype is regulated by estrogen in thyroid cells. Research Support, N.I.H., Extramural

Research Support, Non-U.S. Gov't. Thyroid. Jan 2010;20(1):33-41. doi:10.1089/thy.2009.0296

22. Kim JJ, Kurita T, Bulun SE. Progesterone action in endometrial cancer, endometriosis, uterine fibroids, and breast cancer. Research Support, N.I.H., Extramural

Review. Endocr Rev. Feb 2013;34(1):130-62. doi:10.1210/er.2012-1043

23. Bouman A, Heineman MJ, Faas MM. Sex hormones and the immune response in humans. Review. Hum Reprod Update. Jul-Aug 2005;11(4):411-23. doi:10.1093/humupd/dmi008 
24. Lee ML, Chen GG, Vlantis AC, Tse GM, Leung BC, van Hasselt CA. Induction of thyroid papillary carcinoma cell proliferation by estrogen is associated with an altered expression of Bcl-xL. Research Support, Non-U.S. Gov't. Cancer J. Mar-Apr 2005;11(2):113-21. doi:10.1097/00130404-200503000-00006

25. Mahapatra D, Chandra AK. Biphasic action of iodine in excess at different doses on ovary in adult rats. J Trace Elem Med Biol. Jan 2017;39:210-220. doi:10.1016/j.jtemb.2016.10.006

26. Dohan O, De la Vieja A, Paroder V, et al. The sodium/iodide Symporter (NIS): characterization, regulation, and medical significance. Research Support, Non-U.S. Gov't

Research Support, U.S. Gov't, Non-P.H.S.

Research Support, U.S. Gov't, P.H.S.

Review. Endocr Rev. Feb 2003;24(1):48-77. doi:10.1210/er.2001-0029

27. Furlanetto TW, Nguyen LQ, Jameson JL. Estradiol increases proliferation and down-regulates the sodium/iodide symporter gene in FRTL-5 cells. Research Support, Non-U.S. Gov't

Research Support, U.S. Gov't, Non-P.H.S.

Research Support, U.S. Gov't, P.H.S. Endocrinology. Dec 1999;140(12):5705-11. doi:10.1210/endo.140.12.7197

28. Furlanetto TW, Nunes RB, Jr., Sopelsa AM, Maciel RM. Estradiol decreases iodide uptake by rat thyroid follicular FRTL-5 cells. Research Support, Non-U.S. Gov't. Braz J Med Biol Res. Feb 2001;34(2):259-63. doi:10.1590/s0100-879x2001000200015

29. Stoddard FR, 2nd, Brooks AD, Eskin BA, Johannes GJ. lodine alters gene expression in the MCF7 breast cancer cell line: evidence for an anti-estrogen effect of iodine. Int J Med Sci. Jul 8 2008;5(4):18996. doi:10.7150/ijms.5.189

30. Kim JY, Kim KR. Dietary iodine intake and urinary iodine excretion in patients with thyroid diseases. Research Support, Non-U.S. Gov't. Yonsei Med J. Feb 2000;41(1):22-8. doi:10.3349/ymj.2000.41.1.22

31. Malboosbaf R, Hosseinpanah F, Mojarrad M, Jambarsang S, Azizi F. Relationship between goiter and gender: a systematic review and meta-analysis. Meta-Analysis

Research Support, Non-U.S. Gov't

Review

Systematic Review. Endocrine. Jun 2013;43(3):539-47. doi:10.1007/s12020-012-9831-8 
32. Keeping HS, Newcombe AM, Jellinck PH. Modulation of estrogen-induced peroxidase activity in the rat uterus by thyroid hormones. Research Support, Non-U.S. Gov't. J Steroid Biochem. Jan 1982;16(1):459. doi:10.1016/0022-4731(82)90142-x

33. Krassas GE, Poppe K, Glinoer D. Thyroid function and human reproductive health. Research Support, Non-U.S. Gov't

Review. Endocr Rev. Oct 2010;31(5):702-55. doi:10.1210/er.2009-0041

34. Stewart EA, Rein MS, Friedman AJ, Zuchowski L, Nowak RA. Glycoprotein hormones and their common alpha-subunit stimulate prolactin production by explant cultures of human leiomyoma and myometrium. Am J Obstet Gynecol. Feb 1994;170(2):677-83. doi:10.1016/s0002-9378(94)70247-0

35. Baban RS, Al-Zuheiri ST, Farid YY. Prolactin receptors in uterine leiomyomas. Saudi Med J. Nov 2008;29(11):1593-6.

36. Frohlich E, WahI R. MECHANISMS IN ENDOCRINOLOGY: Impact of isolated TSH levels in and out of normal range on different tissues. Review. Eur J Endocrinol. Feb 2016;174(2):R29-41. doi:10.1530/EJE$15-0713$

37. Evans RW, Farwell AP, Braverman LE. Nuclear thyroid hormone receptor in the rat uterus. Comparative Study

Research Support, U.S. Gov't, P.H.S. Endocrinology. Oct 1983;113(4):1459-63. doi:10.1210/endo-113-41459

38. Hulchiy M, Zhang H, Cline JM, Hirschberg AL, Sahlin L. Receptors for thyrotropin-releasing hormone, thyroid-stimulating hormone, and thyroid hormones in the macaque uterus: effects of long-term sex hormone treatment. Research Support, Non-U.S. Gov't. Menopause. Nov 2012;19(11):1253-9. doi:10.1097/gme.0b013e318252e450

39. Kirkland JL, Mukku V, Hardy M, Young R. Evidence for triiodothyronine receptors in human endometrium and myometrium. Comparative Study

Research Support, Non-U.S. Gov't

Research Support, U.S. Gov't, P.H.S. Am J Obstet Gynecol. Jun 15 1983;146(4):380-3. doi:10.1016/00029378(83)90817-7

40. Wegienka G. Are uterine leiomyoma a consequence of a chronically inflammatory immune system? Med Hypotheses. Aug 2012;79(2):226-31. doi:10.1016/j.mehy.2012.04.046

41. De Vito P, Incerpi S, Pedersen JZ, Luly P, Davis FB, Davis PJ. Thyroid hormones as modulators of immune activities at the cellular level. Research Support, Non-U.S. Gov't 
Review. Thyroid. Aug 2011;21(8):879-90. doi:10.1089/thy.2010.0429

42. van den Boogaard E, Vissenberg R, Land JA, et al. Significance of (sub)clinical thyroid dysfunction and thyroid autoimmunity before conception and in early pregnancy: a systematic review. Published Erratum. Hum Reprod Update. Jun 2016;22(4):532-3. doi:10.1093/humupd/dmw003

43. Romitti M, Fabris VC, Ziegelmann PK, Maia AL, Spritzer PM. Association between PCOS and autoimmune thyroid disease: a systematic review and meta-analysis. Endocr Connect. Oct 26 2018;7(11):1158-1167. doi:10.1530/EC-18-0309

44. Weghofer A, Barad DH, Darmon S, Kushnir VA, Gleicher N. What affects functional ovarian reserve, thyroid function or thyroid autoimmunity? Reprod Biol Endocrinol. May 10 2016;14(1):26. doi:10.1186/s12958-016-0162-0

45. Grossmann B, Saur S, Rall K, et al. Prevalence of autoimmune disease in women with premature ovarian failure. Eur J Contracept Reprod Health Care. Feb 2020;25(1):72-75.

doi:10.1080/13625187.2019.1702638

\section{Tables}


Table 1. Characteristics of women with uterine fibroid group or control group in HIRA claim data.

\begin{tabular}{|c|c|c|c|c|c|}
\hline & \multicolumn{4}{|l|}{$1: 1$ matching } & \multirow{2}{*}{$\begin{array}{l}\text { Standardized } \\
\text { Difference }\end{array}$} \\
\hline & Control & $\begin{array}{l}\text { Uterine } \\
\text { fibroid }\end{array}$ & Total & $\begin{array}{l}\mathrm{P}- \\
\text { value }\end{array}$ & \\
\hline $\begin{array}{l}\text { Nunber of } \\
\text { women }\end{array}$ & 21,246 & 21,246 & 42,492 & & \\
\hline $\begin{array}{l}\text { Median age } \\
\text { (years) }\end{array}$ & 40 [35-44] & 40 [35-44] & 40 [35-44] & $0.32^{\mathrm{a}}$ & 0.004 \\
\hline Age (years) & & & & 0.25 & 0.04 \\
\hline $20-24$ & $248(1.2)$ & $247(1.2)$ & $495(1.2)$ & & \\
\hline $25-29$ & $1,489(7)$ & $1,489(7)$ & $2,978(7)$ & & \\
\hline $30-34$ & $3,523(16.6)$ & $3,526(16.6)$ & 7,049 (16.6) & & \\
\hline $35-39$ & $5,120(24.1)$ & $5,117(24.1)$ & $\begin{array}{l}10,237 \\
(24.1)\end{array}$ & & \\
\hline $40-44$ & $5,853(27.5)$ & $6,154(29)$ & $\begin{array}{l}12,007 \\
(28.3)\end{array}$ & & \\
\hline $45-49$ & $5,013(23.6)$ & $4,713(22.2)$ & $9,726(22.9)$ & & \\
\hline SES & & & & 0.557 & -0.006 \\
\hline Mid high SES & 21,029 (99) & $21,041(99)$ & $42,070(99)$ & & \\
\hline LoW SES & $217(1)$ & $205(1)$ & $422(1)$ & & \\
\hline $\begin{array}{l}\text { Region of } \\
\text { residence }\end{array}$ & & & & 0.005 & -0.027 \\
\hline Urban & $12,535(59)$ & $\begin{array}{l}12,818 \\
(60.3)\end{array}$ & $\begin{array}{l}25,353 \\
(59.7)\end{array}$ & & \\
\hline Rural & $8,711(41)$ & 8,428 (39.7) & $\begin{array}{l}17,139 \\
(40.3)\end{array}$ & & \\
\hline $\mathrm{CCl}$ & & & & 0.425 & 0.008 \\
\hline 0 & $\begin{array}{l}17,295 \\
(81.4)\end{array}$ & $\begin{array}{l}17,241 \\
(81.1)\end{array}$ & $\begin{array}{l}34,536 \\
(81.3)\end{array}$ & & \\
\hline 1 & $2,632(12.4)$ & 2,648 (12.5) & $5,280(12.4)$ & & \\
\hline $2 \sim$ & $1,319(6.2)$ & $1,357(6.4)$ & $2,676(6.3)$ & & \\
\hline Menopause & & & & 0.8 & 0.002 \\
\hline No & 20,742 & 20,734 & 41,476 & & \\
\hline & & Page & $\mathrm{s} / 21$ & & \\
\hline
\end{tabular}


HIRA, health insurance review \& assessment Service; SES, socioeconomic status

All values are expressed as median [quartile1-quartile3] or number (\%).

a The Mann-Whitney U test was used for this analysis. 
Table 2. The cases of thyroid disease in women with uterine fibroid group or control group in HIRA claim data (1:1 matching).

1:1 matching

Control Uterine fibroid Total P-value

Nunber of women

21,246

21,246

42,492

Hypothyroidism

No
Yes
Hyperthyroidism

21,159 (99.6)

$87(0.4)$

21,076 (99.2)

$42,235(99.4)$

$170(0.8)$

$257(0.6)$

No

$21,192(99.7)$

Yes

$54(0.3)$

21,187 (99.7)

42,379 (99.7)

Autoimmune thyroid disease

$59(0.3)$

$113(0.3)$

No
Yes
Goiter

No

Yes

$\begin{array}{lll}21,207(99.8) & 21,184(99.7) & 42,391(99.8) \\ 39(0.2) & 62(0.3) & 101(0.2)\end{array}$

0.022

0.638

$<0.001$

Nontoxic single thyroid nodule

No

Yes

Other thyroid disease

No

Yes

Total thyroid disease

No

Yes

Mean time (free thyroid disease) (Days)
$22(0.1)$

$21,224(99.9)$

21,205 (99.8)

$42,429(99.9)$

$63(0.1)$

21,2

\begin{tabular}{lll}
$21,170(99.6)$ & $21,079(99.2)$ & $42,249(99.4)$ \\
\hline $76(0.4)$ & $167(0.8)$ & $243(0.6)$
\end{tabular}

$21,204(99.8) \quad 21,146(99.5) \quad 42,350(99.7)$

$42(0.2) \quad 100(0.5) \quad 142(0.3)$

0.017

$<0.001$

$<0.001$

$<0.001$

\begin{tabular}{|c|c|c|c|}
\hline 21,000 (98.8) & 20,777 (97.8) & 41,777 (98.3) & \\
\hline $246(1.2)$ & 469 (2.2) & 715 (1.7) & \\
\hline $\begin{array}{l}998[495- \\
1,444]\end{array}$ & $\begin{array}{l}1,005[491- \\
1,601]\end{array}$ & $\begin{array}{l}1002[493- \\
1,502]\end{array}$ & $<0.001^{a}$ \\
\hline
\end{tabular}


HIRA, health insurance review \& assessment Service

All values are expressed as mean \pm standard error or number (\%).

a The Mann-Whitney U test was used for this analysis.

Table 3. Stratified cox regression analysis of thyroid disease in patients with uterine fibroid from HIRA data (after matching)

\begin{tabular}{|c|c|c|c|c|c|c|}
\hline & \multicolumn{2}{|l|}{ Unadjusted } & \multicolumn{2}{|c|}{ Adjusted model $1^{\mathrm{a}}$} & \multicolumn{2}{|c|}{ Adjusted model $2^{b}$} \\
\hline & $\mathrm{HR}(95 \% \mathrm{Cl})$ & $\begin{array}{l}\mathrm{P}- \\
\text { value }\end{array}$ & $\mathrm{HR}(95 \% \mathrm{Cl})$ & $\begin{array}{l}\mathrm{P}- \\
\text { value }\end{array}$ & $\mathrm{HR}(95 \% \mathrm{Cl})$ & $\begin{array}{l}\text { P- } \\
\text { value }\end{array}$ \\
\hline Hypothyroidism & $\begin{array}{l}1.448(1.036- \\
2.024)\end{array}$ & 0.03 & $\begin{array}{l}1.431(1.023- \\
2.001)\end{array}$ & 0.036 & $\begin{array}{l}1.431(1.023- \\
2.001)\end{array}$ & 0.036 \\
\hline Hyperthyroidism & $\begin{array}{l}0.676(0.407- \\
1.122)\end{array}$ & 0.13 & $\begin{array}{l}0.667(0.398- \\
1.117)\end{array}$ & 0.124 & $\begin{array}{l}0.667(0.398- \\
1.117)\end{array}$ & 0.124 \\
\hline $\begin{array}{l}\text { Autoimmune thyroid } \\
\text { disease }\end{array}$ & $\begin{array}{l}0.782(0.627- \\
1.861)\end{array}$ & 0.782 & $\begin{array}{l}1.08(0.627- \\
1.861)\end{array}$ & 0.782 & $\begin{array}{l}1.08(0.627- \\
1.861)\end{array}$ & 0.782 \\
\hline Goiter & $\begin{array}{l}1.273(0.578- \\
2.803)\end{array}$ & 0.55 & $\begin{array}{l}1.182(0.53- \\
2.638)\end{array}$ & 0.683 & $\begin{array}{l}1.182(0.529- \\
2.638)\end{array}$ & 0.683 \\
\hline $\begin{array}{l}\text { Nontoxic single } \\
\text { thyroid nodule }\end{array}$ & $\begin{array}{l}1.5(1.033- \\
2.178)\end{array}$ & 0.033 & $\begin{array}{l}1.511(1.037- \\
2.202)\end{array}$ & 0.032 & $\begin{array}{l}1.511(1.037- \\
2.202)\end{array}$ & 0.032 \\
\hline Other thyroid disease & $\begin{array}{l}1.913(1.155- \\
3.167)\end{array}$ & 0.012 & $\begin{array}{l}1.826(1.098- \\
3.036)\end{array}$ & 0.02 & $\begin{array}{l}1.826(1.098- \\
3.036)\end{array}$ & 0.02 \\
\hline Total thyroid disease & $\begin{array}{l}1.417(1.151- \\
1.745)\end{array}$ & 0.001 & $\begin{array}{l}1.393(1.13- \\
1.718)\end{array}$ & 0.002 & $\begin{array}{l}1.393(1.13- \\
1.718)\end{array}$ & 0.002 \\
\hline
\end{tabular}

$\mathrm{CCl}$, Charlson comorbidity index, $\mathrm{Cl}$, confidence interval; HIRA, health insurance review \& assessment service; HR, hazard ratio

a Each thyroid disease Age per 5 years + Low SES + region + CCl + uterine fibroid

b Each thyroid disease $\sim$ Age per 5 years + Low SES + region + CCl + menopause + uterine fibroid

\section{Figures}




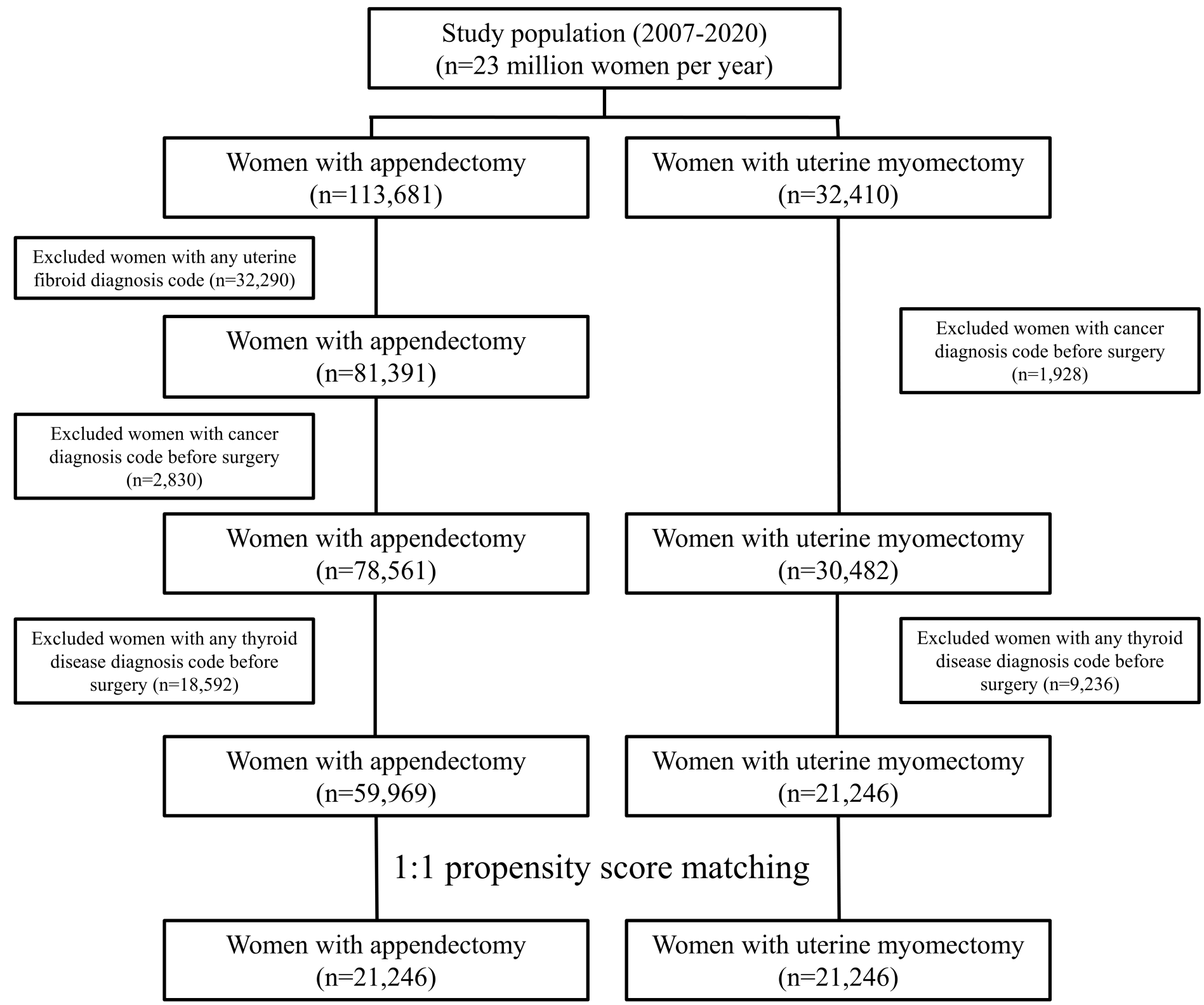

\section{Figure 1}

Flowchart for selecting case and control groups in this study using HIRA data. HIRA, The Health Insurance Review and Assessment Service 


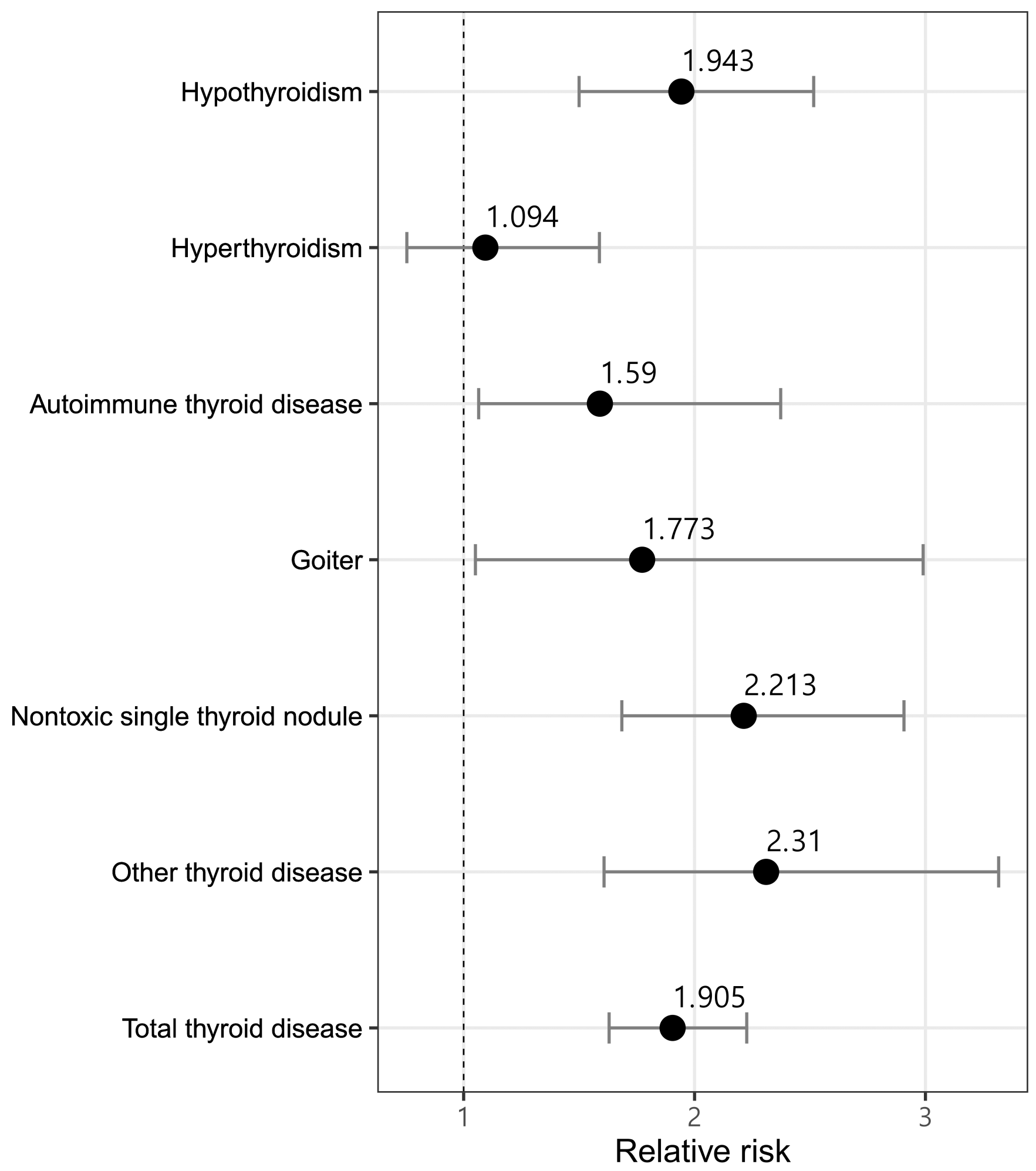

Figure 2

Conditional logistic regression analysiss of thyroid disease in women with uterine fibroid from HIRA data (after matching) 